\title{
The value of alarm features in identifying organic causes of dyspepsia
}

\author{
Lone Galmstrup Madsen MD, Peter Bytzer MD PhD
}

LG Madsen, P Bytzer. The value of alarm features in identifying organic causes of dyspepsia. Can J Gastroenterol 2000;14(8): 713-720. The unaided clinical diagnosis of dyspepsia is of limited value in separating functional dyspepsia from clinically relevant organic causes of dyspepsia (gastric and esophageal malignancies, peptic ulcer disease and complicated esophagitis). The identification of one or more alarm features, such as weight loss, dysphagia, signs of gastrointestinal bleeding, an abdominal mass or age over 45 years may help identify patients with a higher risk of organic disease. This review summarizes the frequency of alarm symptoms in dyspeptic patients in different settings (such as the community, primary care and specialist clinics). The prevalence of alarm features in patients diagnosed with upper gastrointestinal malignancy or peptic ulcer disease is described. The probability of diagnosing clinically relevant upper gastrointestinal disease in patients presenting with alarm features and other risk factors is discussed. Alarm features such as age, significant weight loss, use of nonsteroidal anti-inflammatory drugs, signs of bleeding and dysphagia may help stratify dyspeptic patients and help optimize the use of endoscopy resources.

Key Words: Age; Alarm features; Dyspepsia; Dysphagia; Gastrointestinal bleeding; Helicobacter pylori; NSAID; Vomiting

\section{Valeur des indices dans l'identification des causes organiques de dyspepsie}

RÉSUMÉ : Le diagnostic clinique de dyspepsie sans examen a une valeur plutôt limitée si l'on dissocie la dyspepsie fonctionnelle des causes organiques cliniques de dyspepsie, par exemple une tumeur maligne de l'œsophage ou de l'estomac, un ulcère gastro-duodénal ou une oesophagite compliquée. L'identification d'un ou plusieurs indices comme une perte de poids, la dysphagie, les signes d'hémorragie gastro-intestinale, la présence d'une masse abdominale ou le fait d'avoir plus de 45 ans peut aider à repérer les patients prédisposés à une maladie organique. L'article ci-dessous présente un résumé de la fréquence des indices relevés chez les patients dyspeptiques observés dans différents milieux (cliniques communautaires, spécialisées, centres de soins primaires). Il sera question de la fréquence des indices notés chez les patients chez qui une tumeur maligne du tractus gastro-intestinal supérieur ou un ulcère gastro-duodénal ont été diagnostiqués. L'article traite aussi de la probabilité de poser un diagnostic de maladie gastro-intestinale haute, cliniquement valable, chez les patients qui présentent des indices de maladie et d'autres facteurs de risque. Les indices comme l'âge, une perte de poids importante, l'utilisation d'anti-inflammatoires non stéroïdiens, les signes d'hémorragie et de dysphagie peuvent aider à classer les patients dyspeptiques et à optimiser le recours à l'endoscopie.
$\mathrm{M}$ anagement of the dyspeptic patient who seeks medical care is a great challenge to the physician. Dyspepsia covers a broad spectrum of symptoms with several possible underlying pathophysiological causes. Careful clinical evaluations of symptoms and physical examinations are of limited value in differentiating between peptic ulcer dis- ease, gastroesophageal reflux disease, gastrointestinal malignancy and functional dyspepsia. In only one-third of patients clinically judged to have ulcer disease is the clinical diagnosis confirmed by endoscopy. Moreover, half of all ulcer patients remain undiagnosed by the clinician. Furthermore, one-third of patients with major lesions on endoscopy

This mini-review was prepared from a presentation made at the 1998 World Congress of Gastroenterology, Vienna, Austria, September 6 to 11, 1998 Department of Medical Gastroenterology, Glostrup University Hospital, DK-2600 Glostrup, Denmark

Correspondence and reprints: Dr Peter Bytzer, Department of Medical Gastroenterology, Glostrup University Hospital, DK-2600, Glostrup,

Denmark. Telephone +45-4323-2801,fax+45-4323-3950, e-mail peter.bytzer@dadlnet.dk

Received for publication September 7, 1999. Accepted September 13, 1999 
TABLE 1

Definition and description of traditional alarm features in dyspepsia

\begin{tabular}{ll}
\hline Alarm features & Description \\
\hline Age & Dyspeptic patients older than age 45 to 55 years depending on local incidence of gastric cancer \\
Weight loss & Significant unintended weight loss; usually defined as more than $3 \mathrm{~kg}$ \\
Vomiting & Persistent vomiting in relation to meals and delayed (longer than $1 \mathrm{~h}$ after eating) if occurring repeatedly \\
Dysphagia & The sensation of food being hindered in its passage from the mouth to the stomach; sometimes associated with \\
& odynophagia (pain with swallowing) \\
& Oropharyngeal dysphagia: difficulties in initiating swallowing, including coughing and nasal regurgitation \\
& Esophageal dysphagia: Food stops in or adheres to the esophagus after swallowing \\
Active or chronic bleeding & Gastrointestinal bleeding presenting as: \\
& Hematemesis: Fresh or 'coffee-ground' vomit \\
& Melena: Black, tarry, foul-smelling stools \\
Iron-deficiency anemia: Verified by blood analysis, with no signs or symptoms of bleeding from other sources & Presence of an palpable abdominal mass on physical examination \\
\hline
\end{tabular}

(meaning ulcers, esophagitis or even malignancy) are misclassified as having functional disorders if an unaided clinical diagnosis is trusted (1). To identify dyspeptic patients at higher risk for organic dyspepsia, the identification of alarm symptoms and features may be beneficial. This review examines the value of various alarm features in identifying organic causes of dyspepsia.

\section{ORGANIC CAUSES OF DYSPEPSIA}

Dyspepsia is defined as persistent or recurrent abdominal pain or discomfort centred in the upper abdomen, and is considered to originate in the upper alimentary tract. Organic or structural dyspepsia has been defined as an identifiable pathophysiological cause of dyspepsia, associated with improvement of symptoms if the disease is improved or eliminated (2). The organic causes of dyspepsia cover a wide spectrum of conditions, but for the purposes of this review, only clinically relevant organic causes are considered. These causes include positive endoscopic findings that are potentially relevant to the patient's care, such as malignancy, peptic ulcer disease and complicated esophagitis (strictures, ulcerations and Barrett's metaplasia) (1,3-6). The broader term 'specific organic cause' concerns specific lesions in the upper gastrointestinal tract and includes, for example, the differentiation among types and locations of gastric and esophageal cancers, gastric erosions and gastric and duodenal ulcer diseases; the grading of esophagitis and complications of esophagitis such as ulcers, peptic strictures and Barrett's epithelium; and the typing and grading of gastric polyps, gastritis and dysplasia $(7-10)$.

\section{DYSPEPTIC ALARM SYMPTOMS}

The following symptoms are usually accepted as alarm features when present in the dyspeptic patient: age over 45 to 50 years, depending on the local incidence of gastrointestinal cancer; a significant, unintended weight loss; severe, persistent vomiting; dysphagia, described as a sensation of delay or difficulty in the passage of a food bolus, occasionally associated with pain; active or chronic upper gastrointestinal bleeding presenting as hematemesis (fresh or 'coffee-ground' vomit), melena (black, tarry, foul-smelling stools) or irondeficiency anemia; and a palpable upper abdominal mass (Table 1) (11-15).

Most experts agree that patients having one or more alarm features should be offered prompt endoscopy, whenever possible.

\section{HOW COMMON ARE ALARM SYMPTOMS?}

In the community: The prevalence and incidence of alarm symptoms in dyspeptic persons in the community have not been investigated, to the best of our knowledge.

In primary care: In the Western world, only about onequarter of people with dyspeptic symptoms consult their primary care physician (16). In a Danish primary care study, $10.3 \%$ of 7270 dyspeptic patients consulting their general practitioners presented with one or more alarm symptoms. After an average observation time of 31 months, gastrointestinal diseases such as esophagitis, peptic ulcers, cancer or liver cirrhosis had been diagnosed in only $9 \%$ to $21 \%$, most commonly in patients presenting with black stools (17).

The frequency of organic causes of dyspepsia in primary care has been established in two large-scale Scandinavian studies with 400 and 612 unselected patients, respectively $(18,19)$. A clinically relevant endoscopic diagnosis was found in $32 \%$ to $40 \%$ of the patients presenting with esophagitis (15\% to $23 \%$ ), peptic ulcer disease (13\% to $16 \%$ ), erosive duodenitis $(2 \%)$ or upper gastrointestinal malignancy ( $1 \%$ to $2 \%)$.

In endoscopy clinics: In an effort to reduce the cost of endoscopic procedures, many gastrointestinal units have implemented systems of open access endoscopy, where specialists perform endoscopies without prior consultation. Only a minority of patients who consult their general practitioner because of dyspepsia are referred for endoscopy; hence, study populations from endoscopy units represent a selected subsample from primary care.

In studies from endoscopy units, alarm symptoms such as gastrointestinal bleeding or anemia (19\% to $22 \%$ ), dysphagia (6\% to $16 \%)$, persisting nausea or vomiting $(6 \%)$, anorexia or weight loss $(5 \%)$ and abnormal upper gastrointestinal $\mathrm{x}$-ray 
$(6 \%)$ are frequent referral indications $(5,6,20)$. However, the most common reason for referral is isolated dyspepsia, which accounts for $28 \%$ to $45 \%$ of referrals $(5,6)$. The frequency of clinically relevant endoscopic findings in patients referred for open access endoscopy is 30\% to $60 \%(5,6,21)$. In specialist clinics: Dyspeptic patients referred to gastroenterology specialist units are highly selected, resulting in a higher prevalence of alarm symptoms and organic disease. Procedures requested from gastroenterologists were compared with procedures requested from nongastroenterologists; the frequency of positive findings was significantly higher in endoscopies requested from gastroenterologists $(62 \%)$ than in those requested from nongastroenterologists (52\%) (5).

\section{PREVALENCE OF ALARM SYMPTOMS IN ORGANIC DYSPEPSIA}

Most of the literature on alarm symptoms in dyspepsia is based on retrospective data, resulting in a great risk of recall bias. It is uncertain whether the recorded symptoms led to the examination and to the diagnosis that followed. It is possible that the patient was not aware of a specific symptom before the diagnosis was made, meaning that symptoms other than alarm symptoms were responsible for the referral.

The following section describes the prevalence of alarm symptoms in the organic diseases associated with dyspepsia and the prevalence of organic disease in patients who present with an alarm feature.

Gastric cancer - Age: Gastric cancer is rare in patients younger than 40 years, and the incidence rises with increasing age. In a study of 76 cases of gastric cancer in patients younger than 55 years, only five patients had no alarm symptoms before diagnosis (22). Furthermore, in a retrospective study of 3607 dyspeptic patients under the age of 45 years without alarm symptoms, only two of 17 patients with suspicious lesions at endoscopy had histologically proven gastric carcinoma $(0.055 \%)$ (23). Thus, in young patients with uncomplicated dyspepsia (no alarm features), upper gastrointestinal cancer is extremely rare $(24,25)$.

Weight loss: The most common symptom in gastric cancer is weight loss, which is present in $60 \%$ to $70 \%$ of patients at the time of diagnosis $(22,25,26)$. A study from Norway recorded the amount of weight loss during the time before diagnosis of gastric cancer (27). Only $30 \%$ had no weight loss before diagnosis. Twenty-six per cent had 1 to $5 \mathrm{~kg}$ weight loss and $44 \%$ had weight loss of more than $5 \mathrm{~kg}$; the median weight loss per month was $1.7 \mathrm{~kg}$. Weight loss reduced the probability of gastric resection, from $85 \%$ in patients with no weight loss to $53 \%$ in those who had lost more than $10 \mathrm{~kg}$ preoperatively. In most other studies, the duration and magnitude of weight loss have been poorly defined.

Dysphagia: Dysphagia is usually associated with structural diseases in the esophagus. However, dysphagia has also been reported in $10 \%$ to $30 \%$ of patients with gastric carcinomas $(6,25,26)$, often in patients whose cancer is located in the cardia region and always in patients with more advanced disease (28).
Bleeding: Anemia and signs of upper gastrointestinal bleeding are present in $20 \%$ to $40 \%$ of patients with advanced gastric cancer $(6,25,26)$. In early gastric cancer, anemia is uncommon at presentation, and a history of bleeding is present in less than $25 \%$ (28).

Vomiting: Persistent vomiting and nausea are present in about one-third of patients with gastric cancer, most often in advanced stages or when a tumour invades the pylorus (29. $31)$. In early gastric cancer, only $8 \%$ to $10 \%$ of patients report anorexia, nausea or vomiting $(28,31)$.

Palpable abdominal mass: There are no physical findings associated with early stages of gastric cancer. The presence of a palpable abdominal mass generally indicates longstanding growth with regional extension and is only present in $5 \%$ of those with advanced gastric cancer $(26,31)$.

Other risk factors for gastric cancer: The incidence of gastric cancer is decreasing worldwide, but countries such as Japan, China, Russia and South America continue to have much higher rates of gastric cancer than Western countries. Over the past 50 years in the United States, the incidence of gastric cancer has declined from 33 to 10 cases per $10^{5}$ men and from 30 to five cases per $10^{5}$ women. Racial and ethnic background are also important. In the United States, African Americans, Hispanic Americans and Native Americans are 1.5 to 2.5 times more likely to have gastric carcinoma than white Americans (29), and the disease remains approximately twice as common in men as in women.

Considerable evidence supports a genetic role in the pathogenesis of gastric cancer. Case-control studies indicate that first-degree relatives (eg, parents or siblings) have a twofold to threefold increased risk of contracting the disease $(32,33)$. This suggests that a family history for gastric cancer should be observed in approximately $10 \%$ to $15 \%$ of the registered cases (33).

Epidemiological studies have demonstrated a statistically significant relation between the seroprevalence of Helicobacter pylori, and incidence and mortality rates of gastric cancer (34). Many studies report $H$ pylori infection rates of $40 \%$ to $90 \%$ in patients with gastric cancer, depending on local infection rates $(35,36)$. The precise role of $H$ pylori infection in gastric carcinogenesis remains unclear, although it is associated with the development of chronic atrophic gastritis (29), a well established precursor of gastric cancer. Nevertheless, gastric carcinoma develops in only a small proportion of infected persons, and the effects of prevention or treatment of H pylori infection on gastric cancer are unknown.

Onset of dyspeptic symptoms at the time of diagnosis of gastric cancer is common, and $73 \%$ of patients with gastric cancer had a previous history of dyspepsia. Two-thirds of patients had experienced dyspeptic symptoms for more than one year (8).

Esophageal cancer-Age: Compared with patients with gastric cancer, patients with esophageal cancer are, on average, 10 years older at the time of diagnosis. Thus, esophageal cancer is seldom seen in patients younger than 50 to 55 years. In a retrospective study of 73 patients with esophageal cancer (all types) younger than 55 years, all had reported one or more 
alarm symptoms (22). In a Danish study of 1013 patients with adenocarcinoma of the esophagus, only 59 patients $(6 \%)$ were younger than 50 years (37).

Dysphagia, vomiting and weight loss: Dysphagia is the most common esophageal alarm symptom and is present in $60 \%$ to $85 \%$ of patients with esophageal cancer $(6,22)$. Persistent vomiting occurs with increased tumour size and esophageal stricture formation in about one-third of patients (22). Weight loss is reported by $65 \%$ of patients $(22,37)$.

Bleeding and a palpable abdominal mass: Signs of upper gastrointestinal bleeding are not typical of esophageal cancer. In a survey of 73 cancers, $5.5 \%$ presented with anemia and only $2.7 \%$ presented with hematemesis or melena (22). The frequency of abdominal mass in esophageal cancer is unknown, but is more than likely low.

Other risk factors: Gastroesophageal reflux, especially if severe and long-standing, is associated with an increased risk of adenocarcinoma of the esophagus (10). Heartburn, regurgitations or both, occurring at least once a week for five years or more, were reported by $38 \%$ of 356 patients with esophageal cancer (10). The association between reflux symptoms and cancer was present only in patients with esophageal adenocarcinoma and not in patients with squamous cell cancer. Fiftythree per cent of patients with adenocarcinoma and $6 \%$ of patients with squamous cell carcinomas experienced reflux symptoms at night (10). Barrett's esophagus, which predisposes patients to adenocarcinomas (38), was present in $62 \%$ of patients with adenocarcinoma of the esophagus. The true prevalence is probably much higher. Large tumours tend to overgrow and conceal the underlying specialized tissue from which they arise (39).

Peptic ulcer disease: A chronic peptic ulceration (such as a duodenal or gastric ulcer) is present in approximately $15 \%$ to $25 \%$ of cases of new-onset dyspepsia (40).

Age: In a population-based study from Norway, prevalence of peptic ulcerations increased with age, with a pronounced increase in men older than 40 years and in women older than 50 years (41). Peptic ulcer disease is diagnosed in about onethird of all dyspeptic patients over 40 years referred for endoscopy $(9,19,41)$ and in $10 \%$ to $15 \%$ of dyspeptic patients younger than 40 years $(3,11,42)$.

Bleeding: Upper gastrointestinal bleeding is a common alarm symptom in peptic ulcer disease and was present in $16 \%$ of patients with gastric ulcers and $12.5 \%$ of patients with duodenal ulcers in a study of 2900 unselected dyspeptic patients (6).

Other risk factors: In most studies, the prevalence of $\mathrm{H}$ pylori infection is greater than $90 \%$ in patients with duodenal ulcers and $70 \%$ to $90 \%$ in patients with gastric ulcers who are not using nonsteroidal anti-inflammatory drugs (NSAIDs) (43). However, recent reports from a community study and an endoscopy centre suggest that the prevalence of $H$ pylori in duodenal ulcer disease, especially among white patients, is considerably lower than previously reported (44).

Peptic ulcer disease is a relapsing condition, and a history of peptic ulceration was reported by $20 \%$ of patients with peptic ulcers (45). Of patients with duodenal ulcer disease, $60 \%$ to $75 \%$ relapse within one year and almost $100 \%$ relapse within four years (46). The relapse rate is affected by $H$ pylori infection; in patients with uncomplicated peptic ulcers, recurrence rates were reduced to less than $10 \%$ one year after successful eradication therapy (47).

The use of NSAIDs is a risk factor for peptic ulcer disease and an important cause of ulcer complications. In a primary care study, the frequency of NSAID use in dyspeptic patients who had an upper gastrointestinal bleeding event in a oneyear follow-up study was 78\%, compared with only $33 \%$ in the group of nonbleeding dyspeptic patients (48). In a study of 235 patients with life-threatening complications of peptic ulceration (death or emergency surgery), $60 \%$ had been taking NSAIDs (49).

\section{PROBABILITY OF ORGANIC DYSPEPSIA IN PATIENTS WITH ALARM FEATURES}

Patients with alarm symptoms and features are at a higher probability of having organic disease. The following section summarizes the studies evaluating the diagnostic value of identifying alarm features in dyspeptic patients. Because endoscopy is the diagnostic gold standard for investigating dyspepsia, the majority of studies are completed in patients referred for endoscopy and not in unselected patients presenting in primary care, where the majority of decisions about management are made.

The relation of various symptoms and demographic characteristics with organic dyspepsia, and with peptic ulceration in particular, have been tested in a number of predictive score models. At least 10 different models have been published (21,50-61). Unfortunately, no single model has been thoroughly validated, and the predictive value of the various symptoms and signs is thus unclear. In three different score models (malignancy, peptic ulcer and uncomplicated esophagitis) to detect major dyspepsia $(21,54,62)$, a total of six, five and eight predictors, respectively, were selected. Only one predictor (previous peptic ulcer) was found in all three models, and partial overlap was found for another three predictors (age, vomiting and smoking). In models designed to predict peptic ulceration, a total of 20 different predictors have been identified. Age, smoking habits and relief by antacids or food were selected by most models, but total overlap of these models was not found for any single predictor. This is partially due to inherent problems in the designing and building of score models, but is also explained by the confusing similarity in symptom presentation between patients with organic dyspepsia and patients with functional complaints.

Age: Age has traditionally been viewed as an independent alarm feature. The presence of gastric cancer is very rare below the age of 45 years, while its incidence increases rapidly thereafter in Western nations $(22,25,42)$. Data from endoscopy departments and population studies suggest that age over 40 years is an independent risk factor for organic dyspepsia $(24,41,50)$, although not all studies agree $(6)$.

Recent data suggest that concern about overlooking underlying cancer is not a valid reason for endoscopy in patients younger than 55 years of age - at least in Western nations $(22,25)$. However, if a higher age threshold is used, a substan- 
tial number of patients with peptic ulcer disease will likely be missed (23).

Dysphagia: Dysphagia is most commonly related to pathology of the esophagus. In dyspeptic patients reporting dysphagia, $35 \%$ to $74 \%$ had a relevant endoscopic diagnosis $(5,6)$. Dysphagia is the most common symptom in esophageal cancer $(6,22)$ and is present in $18.6 \%$ of patients with esophagitis (6).

A study from 1984 examined 90 patients with true dysphagia, defined as difficulty in swallowing solid foods for at least one week (63). A total of $85 \%$ of the patients had an abnormality, the most common being peptic strictures (36\%), malignant strictures (26\%), hiatal hernias with esophagitis (13\%) and dysmotility disorders (7\%).

Bleeding: Signs of chronic gastrointestinal bleeding were present in $42 \%$ to $53 \%$ of patients with clinically relevant disease in trials from endoscopy clinics $(5,6)$. In two large series, the causes of upper gastrointestinal bleeding have been described $(64,65)$. Peptic ulcer disease was the most common cause ( $36 \%$ to $45 \%$ ), followed by esophageal varices ( $13 \%$ to $15 \%$ ), gastric erosions ( $6 \%$ to $20 \%$ ), esophagitis (4\% to $8 \%$ ), Mallory-Weiss tears (2\% to $7 \%$ ) and neoplasms $(2.6 \%$ to $3.7 \%)$.

Iron-deficiency anemia in patients with no obvious signs of bleeding is generally considered to be caused by occult gastrointestinal bleeding (66). In studies evaluating more than 300 patients with iron-deficiency anemia, lesions of the gastrointestinal tract consistent with chronic blood loss were identified in the esophagus, stomach or duodenum (41\%) (peptic ulcers or severe esophagitis); the small intestine (3\%); and the colon (22\%) (colon cancer and large adenomas) (67-70). Careful evaluation of gastrointestinal symptoms help in determining the workup $(70,71)$, although the disease may not be localized by the evaluation of symptoms $(68,69)$. The role of gastrointestinal evaluations in premenopausal women with iron-deficiency anemia is not settled. A recent retrospective study of 186 premenopausal women with iron-deficiency anemia found that $23(12 \%)$ had serious gastrointestinal lesions, of which $50 \%$ were malignant (gastric or colonic cancer) (71). Although the design of that study limits its generalizability, it shows that gastrointestinal evaluation can lead to important diagnoses, especially in asymptomatic women in whom the severity of iron deficiency anemia is disproportional to menstrual blood loss (66).

Vomiting: The frequency of the detection of organic disease in dyspeptic patients with severe, persistent vomiting is unknown. In patients with vomiting as the cause of referral, endoscopy demonstrated clinically relevant findings in $40 \%$ (5). Vomiting was shown to be a valuable predictor of organic disease in a study evaluating a score model for prediction of the endoscopic diagnosis (21).

Weight loss: Dyspeptic patients reporting a significant (usually greater than $3 \mathrm{~kg}$ ) and unintended weight loss have a higher probability of having organic dyspepsia than those without significant weight loss. Relevant endoscopic findings were found in $30 \%$ to $40 \%$ of patients reporting anorexia and weight loss (amount not specified) $(5,6)$, and gastric cancer is diagnosed significantly more often in patients referred because of loss of appetite and weight loss than in patients without these symptoms at presentation (6).

Other factors associated with increased risk of organic dyspepsia - History of peptic ulcers: In the majority of patients, peptic ulcer disease is a relapsing condition. Thus, a previous peptic ulcer is associated with an increased probability of having organic disease in case of altered symptomatology. In $40.5 \%$ of patients with a previous peptic ulcer, a relevant endoscopic diagnosis was made, most commonly a duodenal $(20.2 \%)$ or a gastric ulcer (13.7\%) (6). Previous peptic ulcer disease was also shown to be a valuable predictor of a new peptic ulcer in studies evaluating a score model for prediction of the endoscopic diagnosis $(21,54,62)$.

In most centres patients with apparently benign gastric ulcers are commonly followed-up until complete healing occurs. The risk of overlooking a shift to malignancy is increased if endoscopy is performed during acid suppressive treatment. The prescription of proton pump inhibitors and $\mathrm{H}_{2}$ blockers without an endoscopic diagnosis may delay or even prevent the diagnosis of early gastric cancer because of rapid symptom control. Avoiding antisecretory drugs one to two weeks before endoscopy does not reduce misclassification (72). A British study showed that one in six patients with gastric cancer had been investigated by endoscopy within the three years before their diagnosis, and the majority of these patients had been on antisecretory medication that may have masked an early stage of the cancer (8).

Hpylori: With noninvasive test methods to detect $H$ pylori, it is possible to screen patients for the presence of infection before endoscopy. A prospective study by $\mathrm{McColl}$ and co-workers (73) demonstrated that a positive $H$ pylori test was a powerful predictor of underlying ulcer disease; a peptic ulcer was diagnosed in $47 \%$ of infected patients compared with only $5 \%$ of noninfected patients.

The relevance of $\mathrm{H}$ pylori status as a predictor for endoscopic diagnosis in dyspeptic patients has been confirmed in a large number of publications. These studies have all tested the policy of restricting gastroscopy to young patients without alarm features who are seropositive for $\mathrm{H}$ pylori (73$84)$. The results of more than 10,000 patients have been reported and the conclusions are remarkably similar: $25 \%$ to $33 \%$ of the investigations can be saved without overlooking serious pathology (85). It is particularly important to note that no cancers are missed and that the detection rate for peptic ulcers is well above $95 \%$.

Use of NSAIDs and low dose acetylsalicylic acid: The United States Food and Drug Administration reports that symptomatic gastrointestinal ulcerations (pain, bleeding and perforation) occur in approximately $2 \%$ to $4 \%$ of patients treated with NSAIDs for one year (86). In contrast, endoscopic clinical research reveals that $10 \%$ to $20 \%$ of patients taking NSAIDs develop gastric ulcerations within the first three months of medication (87-89). The reason for this prevalence is that NSAIDs are extremely common as both over-the-counter and prescribed medications, and that clinical trials using endoscopy are biased by a selection of patients 
having an increased risk of peptic ulcers, diseases and complications. The risk of ulceration is equivalent for all types of NSAIDs, but the relative risk (RR) of ulceration is different depending on the type of NSAID used. Ibuprofen (RR 2.0) and diclofenac (RR 4.2) are less harmful, and indomethacin (RR 11.3) and ketoprofene (RR 23.7) are more harmful (90). Other factors contributing to the risk of NSAIDrelated ulcers are high age (older than 75 years, odds ratio [OR] 8.9; 60 to 75 years, OR 3.5)(91), previous ulcer history (OR 2.5 to 5) $(91,92)$ and dyspeptic symptoms related to NSAID therapy (OR 8.7) (91).

The risk of upper gastrointestinal bleeding caused by acetylsalicylic acid (ASA) is dose-dependent, with an OR of 2.3 for ASA $75 \mathrm{mg}$ and an OR of 3 to 4 for ASA $300 \mathrm{mg}$ daily $(93,94)$. The role of $H$ pylori infection as an additional risk factor for peptic ulcers and associated complications in NSAID users has been debated. A recent case-control study showed that current NSAID users with $H$ pylori infection had an almost twofold risk of bleeding from a peptic ulcer compared with NSAID users without $H$ pylori (95). This is compatible with the results from a randomized trial in which eradication of $H$ pylori before starting NSAID therapy reduced the occurrence of peptic ulcer (96). Other studies have failed to show this relation (97-99).

History of reflux and Barrett's metaplasia: Symptoms of gastroesophageal reflux such as heartburn and regurgitation

\section{REFERENCES}

1. Bytzer P, Hansen JM, Schaffalitzky de Muckadell OB, MalchowMøller A. Predicting endoscopic diagnosis in the dyspeptic patient. The value of predictive score models. Scand J Gastroenterol 1997;32:118-25.

2. Talley NJ, Colin JD, Koch KL, Koch M, Nyren O, Stanghellini V. Functional dyspepsia: A classification with guidelines for diagnosis and management. Gastroenterol Int 1991;4:145-60.

3. Ayoola EA, al-Rashed RS, al-Mofleh IA, al-Faleh FZ, Laajam M. Diagnostic yield of upper gastrointestinal endoscopy in relation to age and gender: a study of 10112 Saudi patients. Hepatogastroenterology 1996;43:409-15.

4. Heaney A, Collins JS, Watson RG. Open access gastroscopy - 3 year experience of a new service. Ir J Med Sci 1998;167:136-7.

5. Zuccaro G Jr, Provencher K. Does an open access system properly utilize endoscopic resources? Gastrointest Endosc 1997;46:15-20.

6. Adang RP, Vismans JF, Talmon JL, Hasman A, Ambergen AW, Stockbrugger RW. Appropriateness of indications for diagnostic upper gastrointestinal endoscopy: association with relevant endoscopic disease. Gastrointest Endosc 1995;42:390-7.

7. Di Gregorio C, Morandi P, Fante R, De Gaetani C. Gastric dysplasia. A follow-up study. Am J Gastroenterol 1993;88:1714-9.

8. Suvakovic Z, Bramble MG, Jones R, Wilson C, Idle N, Ryott J. Improving the detection rate of early gastric cancer requires more than open access gastroscopy: a five year study. Gut 1997;41:308-13.

9. Hallissey MT, Allum WH, Jewkes AJ, Ellis DJ, Fielding JW. Early detection of gastric cancer. BMJ 1990;301:513-5.

10. Lagergren J, Bergstrom R, Lindgren A, Nyren O. Symptomatic gastroesophageal reflux as a risk factor for esophageal adenocarcinoma. N Engl J Med 1999;340:825-31.

11. Quine MA, Bell GD, McCloy RF, Devlin HB, Hopkins A. Appropriate use of upper gastrointestinal endoscopy - a prospective audit. Steering Group of the Upper Gastrointestinal Endoscopy Audit Committee. Gut 1994;35:1209-14.

12. Whitaker MJ, Brun J, Carelli F. Controversy and consensus in the management of upper gastrointestinal disease in primary care. The International Gastro Primary Care Group. Int J Clin Pract 1997;51:239-43. are very common in the general population $(100,101)$. The prevalence of an underlying organic cause of reflux symptoms is not known, but at least half of the patients with reflux symptoms referred for endoscopy have a normally appearing esophagus (38).

The esophageal complications of chronic gastroesophageal reflux are reflux esophagitis, strictures and Barrett's metaplasia. The risk of developing Barrett's metaplasia is associated with the duration of reflux symptoms (102), with an OR of 6.4 in patients having symptoms for more than 10 years.

Lifestyle-associated risk factors: Smoking increases the risk of peptic ulcer disease and gastric cancer. Both gastric and duodenal ulcerations are more common in smokers than in nonsmokers $(103,104)$. In a survey of 1217 unselected patients with dyspepsia, peptic ulcers were found in $24.7 \%$ of smokers, compared with $10.7 \%$ of nonsmokers. There was a progressive increase in the prevalence of gastric and duodenal ulcerations in ex-smokers, light smokers (fewer than 15 cigarettes per day) and heavy smokers (more than 15 cigarettes per day), compared with nonsmokers (103). Also, gastric carcinoma was more frequent in smokers $(3.6 \%)$ than in nonsmokers $(0.6 \%)$ (103); similar results were found in cohort and case-control studies showing a 1.5- to 3.0-fold increase in the risk of gastric cancer among smokers $(105,106)$. Studies of the relation between alcohol consumption and the risk of gastric cancer have been inconclusive $(105,106)$.

13. Axon AT. Chronic dyspepsia: who needs endoscopy? Gastroenterology 1997;112:1376-80.

14. Kellow JE. Organic causes of dyspepsia, and discriminating functional from organic dyspepsia. Baillieres Clin Gastroenterol 1998;12:477-87.

15. Graham DY, Rakel RE, Fendrick AM, et al. Recognizing peptic ulcer disease. Keys to clinical and laboratory diagnosis. Postgrad Med 1999; 105:113-6,121-3,127-8.

16. Talley NJ, Zinsmeister AR, Schleck CD, Melton LJ III. Dyspepsia and dyspepsia subgroups: a population-based study. Gastroenterology 1992;102:1259-68.

17. Meineche-Schmidt V, Jorgensen T. Prognosis of dyspepsia among patients in general practice. The consequence of having one or more alarm symptoms. Gastroenterology 1996;110:A29. (Abst)

18. Heikkinen M, Pikkarainen P, Takala J, Rasanen H, Julkunen R. Etiology of dyspepsia: four hundred unselected consecutive patients in general practice. Scand J Gastroenterol 1995;30:519-23.

19. Hansen JM, Bytzer P, Schaffalitzky De Muckadell OB. Management of dyspeptic patients in primary care. Value of the unaided clinical diagnosis and of dyspepsia subgrouping. Scand J Gastroenterol 1988;33:799-805.

20. Asante MA, Mendall M, Patel P, Ballam L, Northfield TC. A randomized trial of endoscopy vs no endoscopy in the management of seronegative Helicobacter pylori dyspepsia. Eur J Gastroenterol Hepatol 1998;10:983-9.

21. Bytzer P, Schaffalitzky de Muckadell OB. Prediction of major pathologic conditions in dyspeptic patients referred for endoscopy. A prospective validation study of a scoring system. Scand J Gastroenterol 1992;27:987-92.

22. Gillen D, McColl KE. Does concern about missing malignancy justify endoscopy in uncomplicated dyspepsia in patients aged less than 55 ? Am J Gastroenterol 1999;94:2329-30.

23. Breslin N, Thomson AB, Bailey R, et al. Gastric cancer and other endoscopic findings in young patients with dyspepsia. Gastroenterology 1998;114:A570. (Abst)

24. Williams B, Luckas M, Ellingham JH, Dain A, Wicks AC. Do young patients with dyspepsia need investigation? Lancet 1998;ii:1349-51.

25. Christie J, Shepherd NA, Codling BW, Valori RM. Gastric cancer 
below the age of 55: implications for screening patients with uncomplicated dyspepsia. Gut 1997;41:513-7.

26. Wanebo HJ, Kennedy BJ, Chmiel J, Steele G Jr, Winchester D, Osteen R. Cancer of the stomach. A patient care study by the American College of Surgeons. Ann Surg 1993;218:583-92.

27. Haugstvedt TK, Viste A, Eide GE, Soreide O. Factors related to and consequences of weight loss in patients with stomach cancer. The Norwegian Multicenter experience. Norwegian Stomach Cancer Trial. Cancer 1991;67:722-9.

28. Everett SM, Axon AT. Early gastric cancer in Europe. Gut 1997;41:142-50.

29. Fuchs CS, Mayer RJ. Gastric carcinoma. N Engl J Med 1995;333:32-41.

30. Longmire WPJ. A current view of gastric cancer in the US. Ann Surg 1993;218:579-82.

31. Luk G. Tumors of the stomach. In: Feldman M, Schaschmidt B, Sleisenger M, eds. Sleisenger \& Fordtrand's Gastrointestinal and Liver Disease, 6th edn. Philadelphia: WB Saunders Company, 1998:733-57.

32. La Vecchia C, Negri E, Franceschi S, Gentile A. Family history and the risk of stomach and colorectal cancer. Cancer 1992;70:50-5.

33. Zanghieri G, Di Gregorio C, Sacchetti C, et al. Familial occurrence of gastric cancer in the 2-year experience of a population-based registry. Cancer 1990;66:2047-51.

34. The EUROGAST Study Group. An international association between Helicobacter pylori infection and gastric cancer. Lancet 1993;341:1359-62.

35. Hayes N, O'Hanlon D, Karat D, Scott D, Griffin SM. Helicobacter pylori infections are significantly more common in association with tumours of the gastric antrum than tumours of cardia. Gut 1995;37(Suppl 2):W26. (Abst)

36. Malaty HM, Kim JG, El-Zimaity HM, Graham DY. High prevalence of duodenal ulcer and gastric cancer in dyspeptic patients in Korea. Scand J Gastroenterol 1997;32:751-4.

37. Bytzer P, Christensen PB, Damkier P, Vinding K, Seersholm N. Adenocarcinoma of the esophagus and Barrett's esophagus: a population-based study. Am J Gastroenterol 1999;94:86-91.

38. Fennerty MB, Castell D, Fendrick AM, et al. The diagnosis and treatment of gastroesophageal reflux disease in a managed care environment, Suggested disease management guidelines. Arch Intern Med 1996;156:477-84.

39. Cameron AJ, Lomboy CT, Pera M, Carpenter HA. Adenocarcinoma of the esophagogastric junction and Barrett's esophagus. Gastroenterology 1995;109:1541-6.

40. Talley NJ, Silverstein MD, Agreus L, Nyren O, Sonnenberg A, Holtmann G. AGA technical review: evaluation of dyspepsia. American Gastroenterological Association. Gastroenterology 1998;114:582-95.

41. Bernersen B, Johnsen R, Straume B. Non-ulcer dyspepsia and peptic ulcer: the distribution in a population and their relation to risk factors. Gut 1996;38:822-5.

42. Forbat LN, Gribble RJ, Baron JH. Gastrointestinal endoscopy in the young. Br Med J (Clin Res Ed) 1987;295:365

43. Vaira D, Menegatti M, Miglioli M. What is the role of Helicobacter pylori in complicated ulcer disease? Gastroenterology 1997;113(6 Suppl):S78-84.

44. Jyotheeswaran S, Shah AN, Jin HO, Potter GD, Ona FV, Chey WY. Prevalence of Helicobacter pylori in peptic ulcer patients in greater Rochester, NY: is empirical triple therapy justified? Am J Gastroenterol 1998;93:574-8.

45. Adang RP, Ambergen AW, Talmon JL, Hasman A, Vismans JF, Stockbrugger RW. The discriminative value of patient characteristics and dyspeptic symptoms for upper gastrointestinal endoscopic findings: a study on the clinical presentation of 1,147 patients. Digestion 1996;57:118-34.

46. Lane MR, Lee SP. Recurrence of duodenal ulcer after medical treatment. Lancet 1988;i:1147-9.

47. Hopkins RJ, Girardi LS, Turney EA. Relationship between Helicobacter pylori eradication and reduced duodenal and gastric ulcer recurrence: a review. Gastroenterology 1996;110:1244-52.

48. Kurata JH, Nogawa AN, Noritake D. NSAIDs increase risk of gastrointestinal bleeding in primary care patients with dyspepsia. J Fam Pract 1997;45:227-35.

49. Armstrong CP, Blower AL. Non-steroidal anti-inflammatory drugs and life threatening complications of peptic ulceration. Gut 1987;28:527-32.

50. Johannessen T, Petersen H, Kleveland PM, et al. The predictive value of history in dyspepsia. Scand J Gastroenterol 1990;25:689-97.
51. Crean GP, Card WI, Beattie AD, et al. "Ulcer-like dyspepsia". Scand J Gastroenterol Suppl 1982;79:9-15.

52. Davenport PM, Morgan AG, Darnborough A, De Dombal FT. Can preliminary screening of dyspeptic patients allow more effective use of investigational techniques? Br Med J (Clin Res Ed) 1985;290:217-20.

53. Talley NJ, McNeil D, Piper DW. Discriminant value of dyspeptic symptoms: a study of the clinical presentation of 221 patients with dyspepsia of unknown cause, peptic ulceration, and cholelithiasis. Gut 1987;28:40-6.

54. Mann J, Holdstock G, Harman M, Machin D, Loehry CA. Scoring system to improve cost effectiveness of open access endoscopy. Br Med J (Clin Res Ed) 1983;287:937-40.

55. Horrocks JC, de Dombal FT. Computer-aided diagnosis of "dyspepsia". Am J Dig Dis 1975;20:397-406.

56. Horrocks JC, De Dombal FT. Diagnosis of dyspepsia from data collected by a physician's assistant. Br Med J 1975;3:421-3.

57. Ross P, Dutton AM. Computer analysis of symptom complexes in patients having upper gastrointestinal examinations. Am J Dig Dis 1972;17:248-54.

58. Spiegelhalter DJ. Statistical methodology for evaluating gastrointestinal symptoms. Clin Gastroenterol 1985;14:489-515.

59. Spiegelhalter DJ, Crean GP, Holden R, Knill-Jones RP. Taking a calculated risk: predictive scoring systems in dyspepsia. Scand J Gastroenterol Suppl 1987;128:152-60.

60. Naji SA, Brunt PW, Hagen S, et al. Improving the selection of patients for upper gastrointestinal endoscopy. Gut 1993;34:187-91.

61. Marton KI, Sox HC Jr, Wasson J, Duisenberg CE. The clinical value of the upper gastrointestinal tract roentgenogram series. Arch Intern Med 1980;140:191-5.

62. Marrero JM, Jazrawi R, Goggin P, Finch P, Northfield TC. A simple questionnaire as a method for reducing workload from open access endoscopy. Gut 1990;31:A1205. (Abst)

63. Wilkins WE, Walker J, McNulty MR, Britton DC, Gough KR. The organisation and evaluation of an open-access dysphagia clinic. Ann R Coll Surg Engl 1984;66:115-6.

64. Silverstein FE, Gilbert DA, Tedesco FJ, Buenger NK, Persing J. The national ASGE survey on upper gastrointestinal bleeding. II. Clinical prognostic factors. Gastrointest Endosc 1981;27:80-93.

65. Morgan AG, Clamp SE. OMGE international upper gastrointestinal bleeding survey, 1978-1986. Scand J Gastroenterol Suppl 1988;144:51-8.

66. Rockey DC. Occult gastrointestinal bleeding. N Engl J Med 1999;341:38-46

67. Cook IJ, Pavli P, Riley JW, Goulston KJ, Dent OF. Gastrointestinal investigation of iron deficiency anaemia. Br Med J (Clin Res Ed) 1986;292:1380-2.

68. Kepczyk T, Kadakia SC. Prospective evaluation of gastrointestinal tract in patients with iron-deficiency anemia. Dig Dis Sci 1995;40:1283-9.

69. McIntyre AS, Long RG. Prospective survey of investigations in outpatients referred with iron deficiency anaemia. Gut 1993;34:1102-7.

70. Rockey DC, Cello JP. Evaluation of the gastrointestinal tract in patients with iron-deficiency anemia. N Engl J Med 1993;329:1691-5.

71. Bini EJ, Micale PL, Weinshel EH. Evaluation of the gastrointestinal tract in premenopausal women with iron deficiency anemia. Am J Med 1998;105:281-6.

72. Griffin SM, Raimes SA. Proton pump inhibitors may mask early gastric cancer. Dyspeptic patients over 45 should undergo endoscopy before these drugs are started. BMJ 1998;317:1606-7.

73. McColl KE, el-Nujumi A, Murray L, et al. The Helicobacter pylori breath test: a surrogate marker for peptic ulcer disease in dyspeptic patients. Gut 1997;40:302-6.

74. Sobala GM, Crabtree JE, Pentith JA, et al. Screening dyspepsia by serology to Helicobacter pylori. Lancet 1991;338:94-6.

75. Patel P, Mendall MA, Khulusi S, et al. Salivary antibodies to Helicobacter pylori: screening dyspeptic patients before endoscopy. Lancet 1994;344:511-2.

76. Perri F, Clemente R, Latiano A, et al. Urea breath test as first choice test in dyspepsia: A money and time sparing approach. Gut 1995;37(Suppl 2):A203. (Abst)

77. Mendall MA, Jazrawi RP, Marrero JM, et al. Serology for Helicobacter pylori compared with symptom questionnaires in screening before direct access endoscopy. Gut 1995;36:330-3.

78. Patel P, Khulusi S, Mendall MA, et al. Prospective screening of 
dyspeptic patients by Helicobacter pylori serology. Lancet 1995;346:1315-8.

79. Kapoor K, Yapp T, Thomas G, Swift J, Pugh S. Is endoscopic diagnosis necessary before $H$ pylori (HP) eradication therapy? Gut 1995;37(Suppl 2):A85-6. (Abst)

80. Fraser AG, Ali MR, McCullough S, Yeates NJ, Haystead A. Diagnostic tests for Helicobacter pylori - can they help select patients for endoscopy? N Z Med J 1996;109:95-8.

81. Reilly T, Stone D, Poxon V, Elliott T, Walt R. H pylori serology in the investigation of dyspepsia. A general practice based follow-up study. Gut 1996;38(Suppl 1):A65. (Abst)

82. Vaira D, Stanghellini V, Menegatti M, Palli D, Corinaldesi R, Miglioli M. Prospective screening of dyspeptic patients by Helicobacter pylori serology: a safe policy? The Italian Helicobacter pylori Study Group. Endoscopy 1997;29:595-601.

83. Moayyedi P, Carter AM, Catto A, Heppell RM, Grant PJ, Axon AT. Validation of a rapid whole blood test for diagnosing Helicobacter pylori infection. BMJ 1997;314:119.

84. Heikkinen M, Janatuinen E, Mayo K, Megraud F, Julkunen R, Pikkarainen P. Usefulness of anti-Helicobacter pylori and anti-CagA antibodies in the selection of patients for gastroscopy. Am J Gastroenterol 1997;92:2225-9.

85. Bytzer P. How should new-onset dyspepsia be managed in general and specialist practice? Baillieres Clin Gastroenterol 1998;12:587-99.

86. Cryer B. Nonsteroidal anti-inflammatory drugs and gastrointestinal disease. In: Feldman M, Schaschmidt B, Sleisenger M, eds. Sleisenger \& Fordtran's Gastrointestinal and Liver Disease, 6th edn. Philadelphia: WB Saunders Company, 1998:343-57.

87. Graham DY, Agrawal NM, Roth SH. Prevention of NSAID-induced gastric ulcer with misoprostol: multicentre, double-blind, placebocontrolled trial. Lancet 1988;ii:1277-80.

88. Ehsanullah RS, Page MC, Tildesley G, Wood JR. Prevention of gastroduodenal damage induced by non-steroidal anti-inflammatory drugs: controlled trial of ranitidine. Br Med J 1988;297:1017-21.

89. Graham DY, White RH, Moreland LW, et al. Duodenal and gastric ulcer prevention with misoprostol in arthritis patients taking NSAIDs. Misoprostol Study Group. Ann Intern Med 1993;119:257-62.

90. Langman MJ, Weil J, Wainwright P, et al. Risks of bleeding peptic ulcer associated with individual non-steroidal anti-inflammatory drugs. Lancet 1994;343:1075-8.

91. Hansen JM, Hallas J, Lauritsen JM, Bytzer P. Non-steroidal antiinflammatory drugs and ulcer complications: a risk factor analysis for clinical decision-making. Scand J Gastroenterol 1996;31:126-30.

92. Taha AS, Dahill S, Sturrock RD, Lee FD, Russell RI. Predicting NSAID related ulcers - assessment of clinical and pathological risk factors and importance of differences in NSAID. Gut 1994:35:891-5.

93. Weil J, Colin-Jones D, Langman M, et al. Prophylactic aspirin and risk of peptic ulcer bleeding. BMJ 1995;310:827-30.

94. Slattery J, Warlow CP, Shorrock CJ, Langman MJ. Risks of gastrointestinal bleeding during secondary prevention of vascular events with aspirin - analysis of gastrointestinal bleeding during the UK-TIA trial. Gut 1995;37:509-11.

95. Aalykke C, Lauritsen JM, Hallas J, Reinholdt S, Krogfelt K, Lauritsen K. Helicobacter pylori and risk of ulcer bleeding among users of nonsteroidal anti-inflammatory drugs: a case-control study. Gastroenterology 1999;116:1305-9.

96. Chan FK, Sung JJ, Chung SC, et al. Randomised trial of eradication of Helicobacter pylori before non-steroidal anti-inflammatory drug therapy to prevent peptic ulcers. Lancet 1997;350:975-9.

97. Hawkey CJ, Tulassay Z, Szczepanski L, et al. Randomised controlled trial of Helicobacter pylori eradication in patients on non-steroidal antiinflammatory drugs: HELP NSAIDs study. Helicobacter Eradication for Lesion Prevention. Lancet 1998;352:1016-21.

98. Lai K, Lam SK, Hui W, et al. Can eradication of Helicobacter pylori prevent future development of peptic ulcers in patients recieving longterm continuous nonsteroidal antiinflammatory drugs. Gastroenterology 1998;114:A192. (Abst)

99. Lai K, Lam SK, Hui W, et al. Eradication of Helicobacter pylori did not accelerate the healing of gastric and duodenal ulcers/erosions in patients on long-term continuous nonsteroidal anti-inflammatory drugs. Gastroenterology 1998;114:A192. (Abst)

100. Jones RH, Lydeard SE, Hobbs FD, et al. Dyspepsia in England and Scotland. Gut 1990;31:401-5.

101. Jones R. Gastro-oesophageal reflux disease in general practice. Scand J Gastroenterol Suppl 1995;211:35-8.

102. Lieberman DA, Oehlke M, Helfand M. Risk factors for Barrett's esophagus in community-based practice. GORGE consortium. Gastroenterology Outcomes Research Group in Endoscopy. Am J Gastroenterol 1997;92:1293-7.

103. Ainley CC, Forgacs IC, Keeling PW, Thompson RP. Outpatient endoscopic survey of smoking and peptic ulcer. Gut 1986;27:648-51.

104. Kaneko E, Ooi S, Ito G, Honda N. Natural history of duodenal ulcer detected by the gastric mass surveys in men over 40 years of age. Scand J Gastroenterol 1989;24:165-70.

105. Chyou PH, Nomura AM, Hankin JH, Stemmermann GN. A casecohort study of diet and stomach cancer. Cancer Res 1990;50:7501-4.

106. Nomura A, Grove JS, Stemmermann GN, Severson RK. A prospective study of stomach cancer and its relation to diet, cigarettes, and alcohol consumption. Cancer Res 1990;50:627-31. 


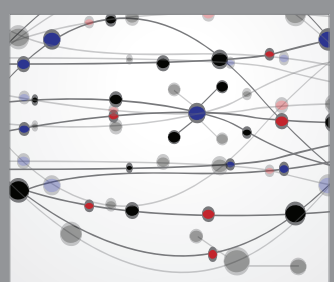

The Scientific World Journal
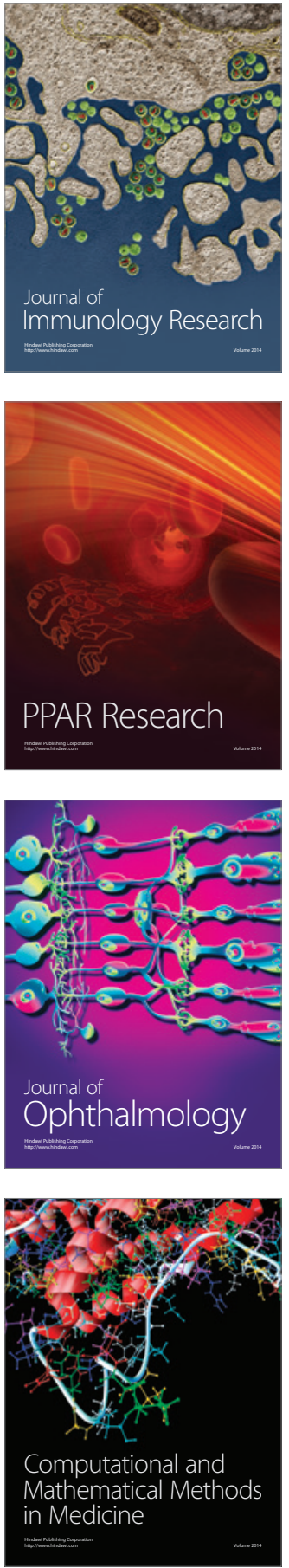

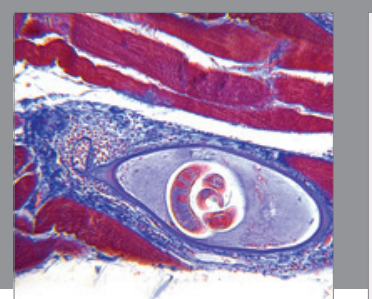

Gastroenterology Research and Practice

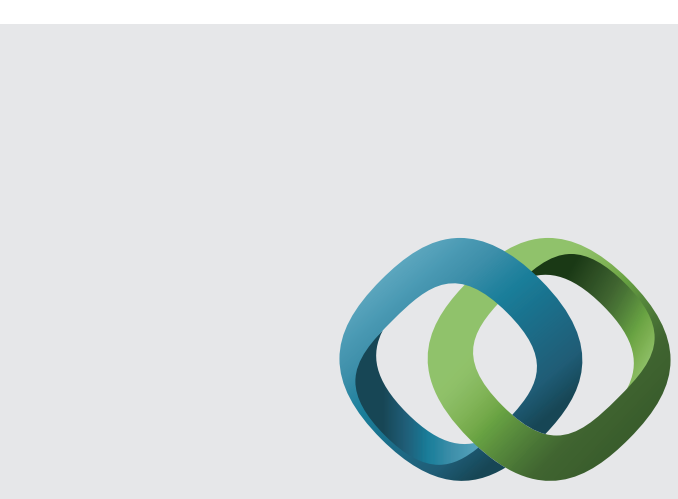

\section{Hindawi}

Submit your manuscripts at

http://www.hindawi.com
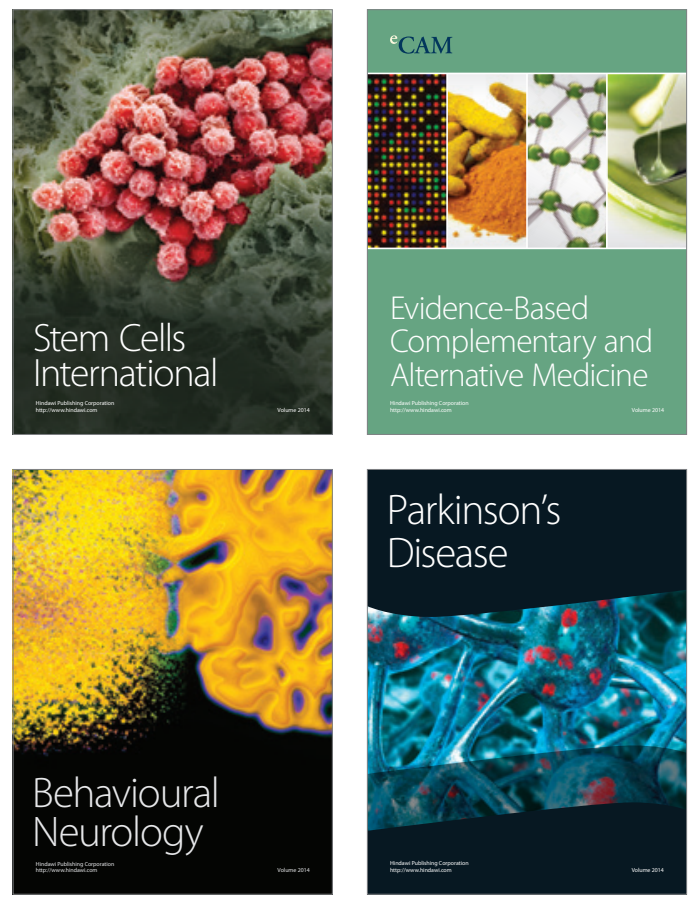
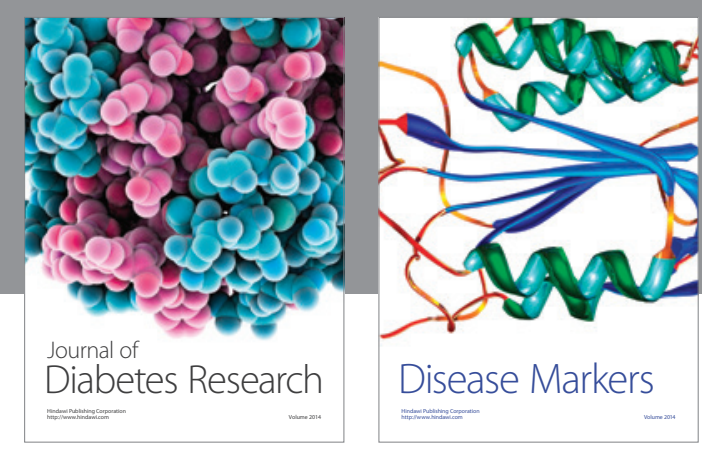

Disease Markers
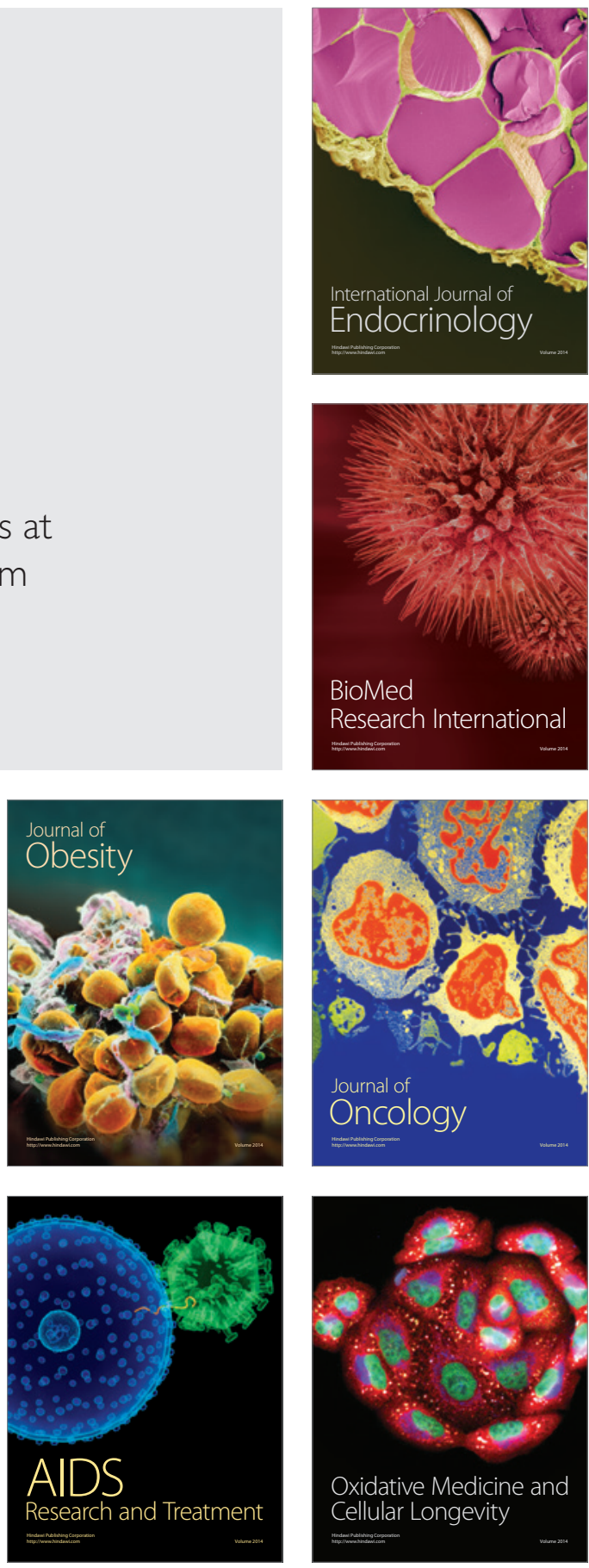